\title{
The novel protective role of P27 in MLN4924-treated gastric cancer cells
}

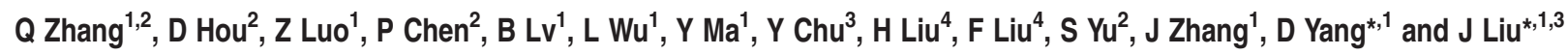

The tumor-suppressor gene cyclin-dependent kinase inhibitor 1B (P27) is downregulated in gastric cancer cells mainly through proteolytic degradation mediated by the SKP-Cullin1-F-Box (SCF) complex. But the correlation between its downregulation and gastric cancer prognosis still remains indefinite. MLN4924, an anti-tumor agent, which suppresses the SCF complex by inhibiting Cullin1 neddylation, emerges as a promising tool to elucidate its functions in gastric cancer cells. In this study, MLN4924 induced significant growth inhibition of gastric cancer cells in a dose-dependent manner, along with the simultaneous accumulation of P27 and cell cycle abnormalities such as G2/M arrest. Importantly, we found that P27 silencing in MLN4924-treated cells resulted in an enhancement of growth inhibition both in vitro and in vivo. Mechanism analysis revealed the antagonism effects of antioxidants to this excess apoptosis, suggesting reactive oxygen species (ROS) overproduction especially in the mitochondria was the principal cause of the augmentation. Moreover, the robust ROS attacked the mitochondria to initiate collapse of the mitochondrial membrane permeability and the exportation of apoptosis-inducing factor (AIF), IAP-binding mitochondrial protein (SMAC/DIABLO) and cytochrome c. Finally, we also found that P27 knockdown affected the expression profile of several critical BH3 family members to amplify the mitochondrial dysfunction and apoptosis. In summary, our findings unveiled a protective role of P27 by maintaining mitochondrial membrane permeability in MLN4924-treated gastric cancer cells, and therefore highlighted the potential combination of MLN4924 with P27 inhibition to improve its therapeutic efficacy.

Cell Death and Disease (2015) 6, e1867; doi:10.1038/cddis.2015.215; published online 27 August 2015

Gastric cancer is a heavy burden to public health as its overall mortality ranked third in cancer-related deaths worldwide in 2012. ${ }^{1}$ Its asymptomatic progression in early stages often leads to delayed diagnosis and hence the poor prognosis of patients. Given the previous studies that demonstrated that S-phase kinase-associated protein 2 (SKP2) and Cullin1 (CUL1) were tightly connected with the progression of gastric cancer, ${ }^{2-4}$ the neddylation inhibitor MLN4924, specifically suppressing the functions of the SKP2-CUL1-F-box (SCF) complexes by blocking the CUL1 neddylation, is therefore a promising drug for the chemotherapy of gastric cancer. ${ }^{5}$

Cyclin-dependent kinase inhibitor 1B (P27) from the Cip/Kip family is a well-defined substrate for the ubiquitin ligase activity of SCF complex, ${ }^{6-8}$ and has a central role in cell cycle regulation. ${ }^{9}$ By getting incorporated into the CDK4/6-Cyclin D complex or the CDK2-Cyclin E/A complex, P27 restrains the $G 1$ phase initiation and $G 1 / S$ transition. ${ }^{10-13}$ In vivo studies which reported organ hyperplasia in P27-/- mice confirmed the function of P27 as a tumor-suppressor gene with haplo-insufficient effects. ${ }^{14-17}$ Numerous pathological studies have verified the P27 downregulation in various tumors, including breast, ${ }^{18}$ colon, ${ }^{19}$ lung, ${ }^{20}$ liver $^{21}$ and stomach. $^{22}$ In contrast to the positive correlations between P27 decline and tumor progression in other organs, the relationship of P27 expression and the prognosis of gastric cancer still remains controversial. ${ }^{23-25}$

Different from other tumor-suppressor genes, the decreased protein level of P27 in tumors was mainly due to the degradation mediated by the over-activated SCF complexes rather than DNA mutations. ${ }^{16,26}$ In this study, we applied MLN4924 to investigate the functions of P27 as an important substrate of SCF complex in gastric cancer cells. Upon the cytotoxicity of MLN4924, P27 silencing in treated cells increased the mitochondrial reactive oxygen species (ROS) overproduction which initiated the synergic responses of $\mathrm{BH} 3$ family members and the release of mitochondrial apoptotic substances. These effects stimulated the mitochondrial membrane permeability collapse and activated intrinsic apoptotic signals to enhance the MLN4924-induced apoptosis. Our findings for the first time revealed the protective role of P27 in MLN4924-treated gastric cancer cells. Moreover, it emphasized the involvement of P27 in maintaining mitochondrial membrane permeability and the potential combination of MLN4924 with P27 inhibition to improve its therapeutic efficacy.

\footnotetext{
${ }^{1}$ Department of Digestive Diseases, Huashan Hospital, Fudan University, Shanghai, China; ${ }^{2}$ Institutes of Biomedical Sciences of Shanghai Medical School, Fudan University, Shanghai, China; ${ }^{3}$ Department of Immunology, Shanghai Medical College, Fudan University, Shanghai, China and ${ }^{4}$ The Third Department of Hepatic Surgery, Eastern Hepatobiliary Surgery Hospital, Second Military Medical University, Shanghai, China

${ }^{*}$ Corresponding author: D Yang or J Liu, Department of Digestive Diseases, Huashan Hospital, Fudan University, 12 Middle Wulumuqi Road, Shanghai, 200040, China. Tel: +86 15026578969 or +86 1861628 1372; Fax: +86 215288 8236; E-mail: kobesakura@ 163.com or jieliu@fudan.edu.cn

Abbreviations: CDKN1B, Cyclin-dependent kinase inhibitor 1B; SCF complex, SKP2-Cullin1-F-Box Complex; GFP, green fluorescent protein; ROS, reactive oxygen species; AIF, apoptosis-inducing factor; KPC, Kip1 ubiquitination-promoting complex; MMP, mitochondrial membrane potential; MAC, mitochondrial apoptosis-induced channel

Received 09.3.2015; revised 12.6.2015; accepted 16.6.2015; Edited by R Johnstone
} 


\section{Results}

The growth of gastric cancer cells was suppressed by the neddylation inhibitor MLN4924. MLN4924 is a neddylation inhibitor that was reported to be a potential therapeutic agent for several cancers, including leukemia and hepatocellular carcinoma. ${ }^{27,28}$ However, its effect on gastric cancer cells is still unknown. Therefore, we determined the efficacy of MLN4924 in suppressing the growth of two gastric cancer cell lines (AGS and MGC80-3) by cell counting, CCK8 colorimetric assay and colony-formation assay. CUL1 neddylation was blocked by MLN4924 at $0.1 \mu \mathrm{M}$, and this effect appeared only after $24 \mathrm{~h}$ of treatment at $0.3 \mu \mathrm{M}$ (Figure 1a).
The proliferation of AGS and MGC80-3 cells was significantly inhibited in a typical dose-dependent manner (Figures 1b-d, Supplementary Figure S1a). These results confirmed the impaired proliferation of gastric cancer cells by MLN4924.

Cell cycle abnormalities were induced in gastric cancer cells by MLN4924. It has been reported that MLN4924 stabilizes many SCF complex substrates, including cell cyclerelated proteins. Consistent with previous results, we found that MLN4924 led to the accumulation of the SCF complex substrate P27. However, P16 from the INK4A family and its downstream effector RB were unaffected (Figure 2a). Accompanying the P27 upregulation, a large number of
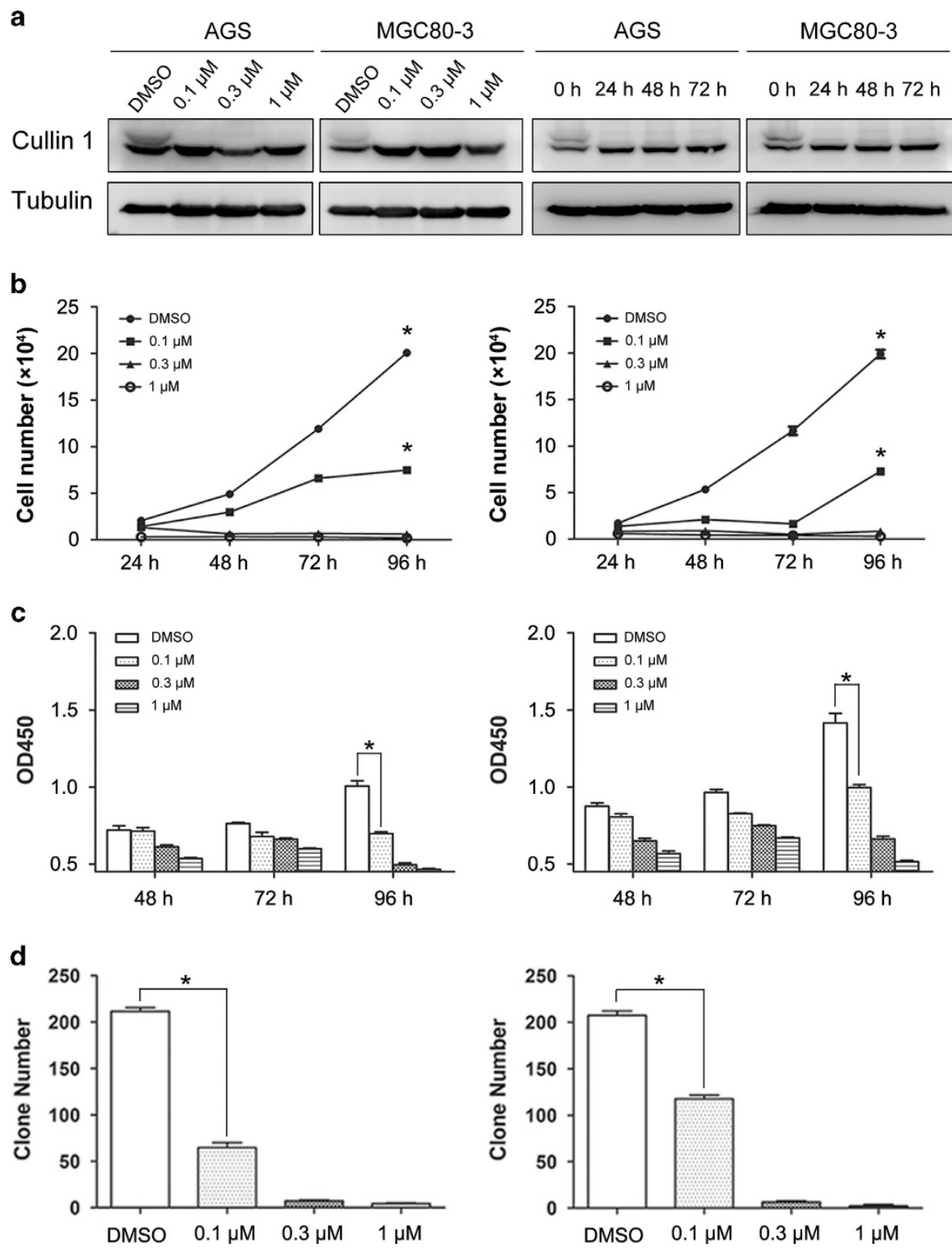

Figure 1 Growth inhibition of gastric cancer cells by MLN4924. (a) MLN4924 inhibited the neddylation of CUL1. AGS and MGC80-3 cells were treated under the indicated MLN4924 concentrations for 24-72 h, and then subjected to immunoblotting analysis of neddylation of CUL1. (b) MLN4924 suppressed the proliferation of gastric cancer cells. AGS and MGC80-3 cells were treated under the indicated MLN4924 concentrations for 24-96 h, then trypsinized and counted at each time point. (c) MLN4924 impaired the viability of gastric cancer cells. AGS and MGC80-3 cells were treated under the indicated MLN4924 concentrations and subjected to CCK8 colorimetric assay to assess their viability. (d) MLN4924 affected the colony-formation ability of gastric cancer cells. AGS and MGC80-3 cells were treated under the indicated MLN4924 concentrations for 9 days and then subjected to colony-formation assay. For panels $\mathbf{b}$ and $\mathbf{c}, n=3$, and for panel $\mathbf{d}, n=4$ 
a

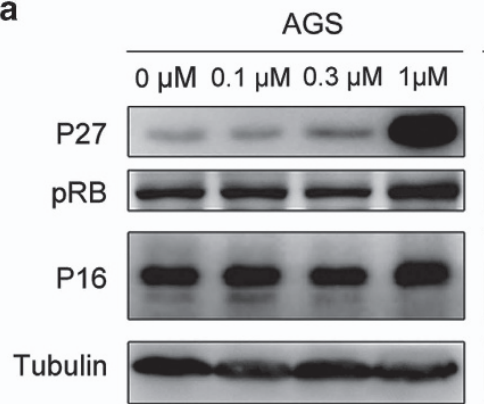

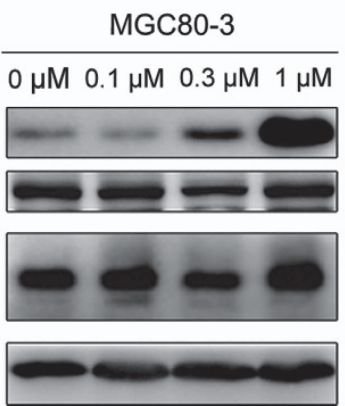

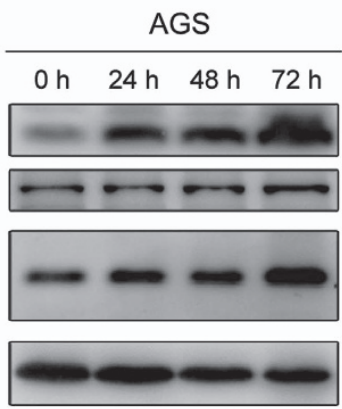

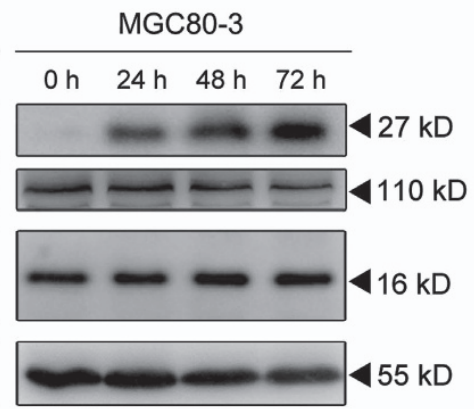

b
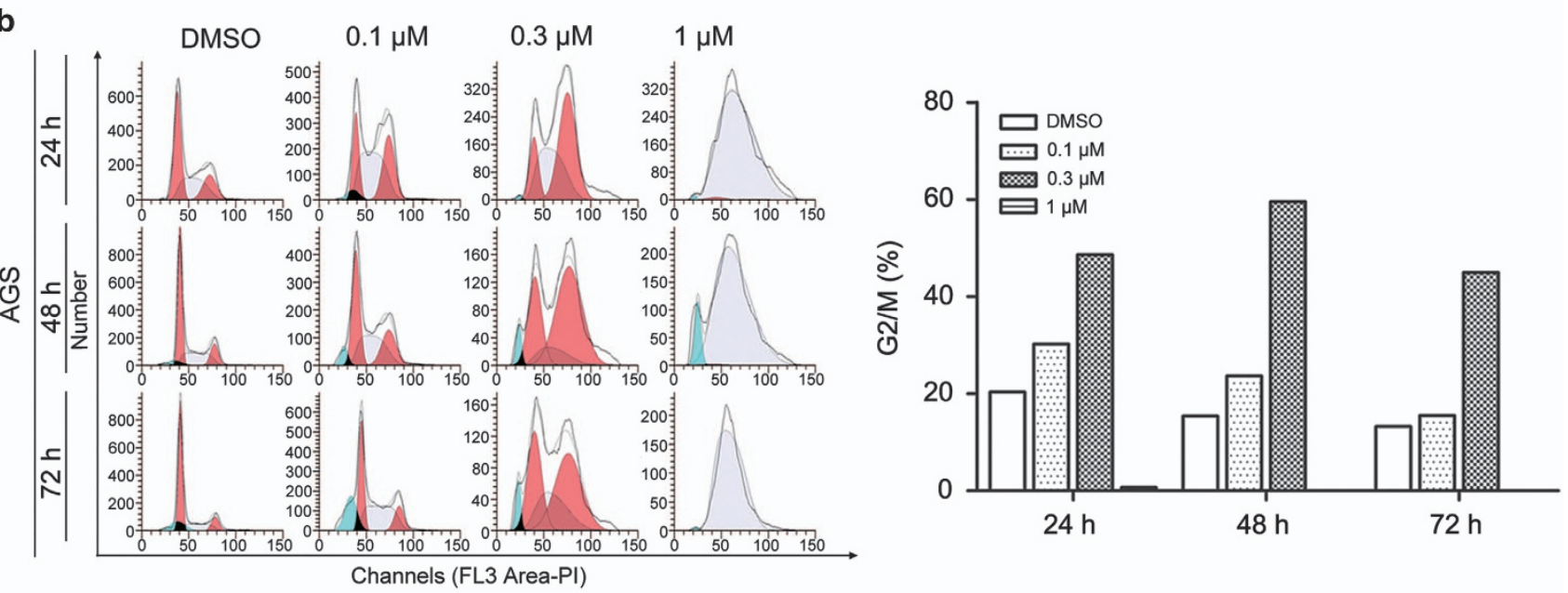

C
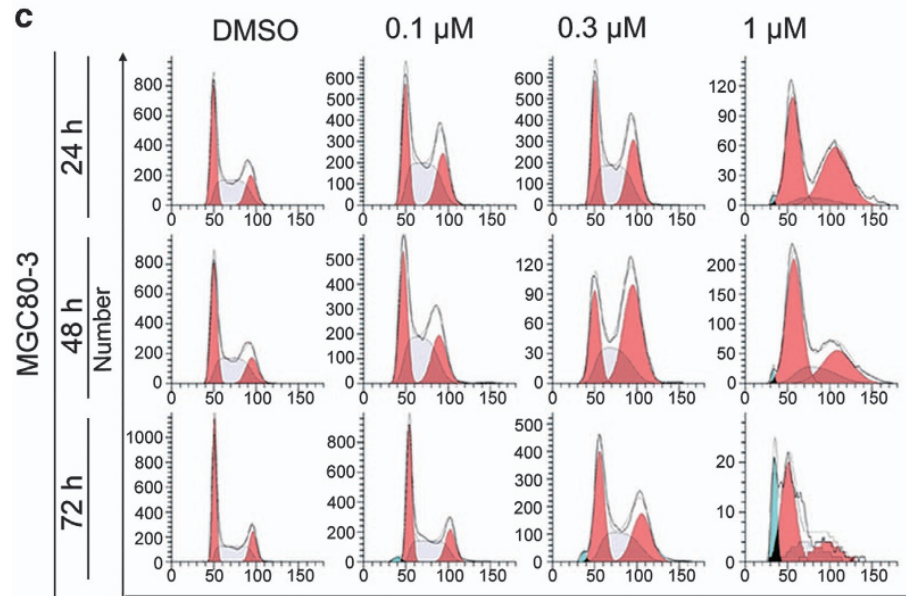

Channels (FL3 Area-PI)

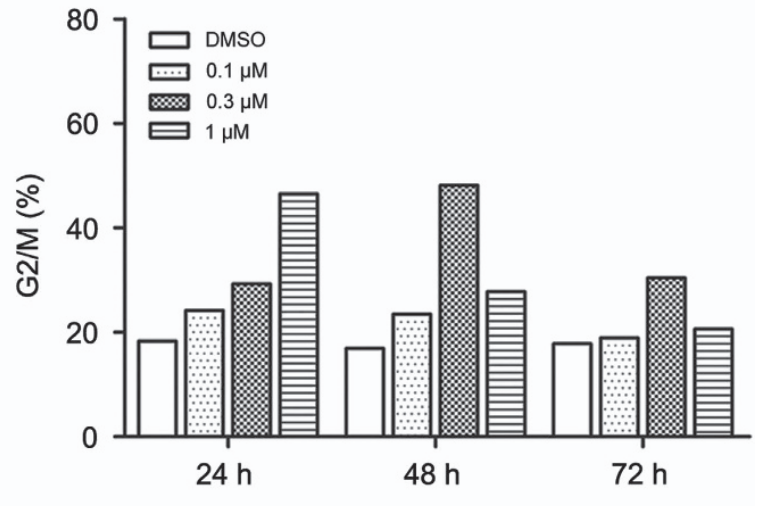

Figure 2 Cell cycle arrest of gastric cancer cells induced by MLN4924. (a) MLN4924 treatment led to the accumulation of senescence-associated proteins. AGS and MGC803 cells were cultured under the indicated MLN4924 concentration gradient for $72 \mathrm{~h}$ (left panel), or treated with $0.3 \mu \mathrm{M}$ MLN4924 and harvested at the indicated time point (right panel). The protein samples were subjected to immunoblotting analysis for the expression of P27, pRB, P16 and tubulin. (b and c) MLN4924 interrupted cell cycle progression at the G2/M phase. AGS and MGC80-3 cells treated with the indicated MLN4924 concentration, and subjected to propidium iodide staining and FCM to determine the cell cycle profile

treated cells were observed to undergo a premature senescence compared with control groups (Supplementary Figure S1b). This observation suggested a critical role of P27 in MLN4924-induced growth inhibition.

Premature senescence is defined as a physiological mechanism that thwarts the proliferation of tumor cells by cell cycle arrest. Propidium iodide staining detected that the proportion of AGS cells arrested in G2/M phase increased as the concentration of MLN4924 was increased from 0.1 to $0.3 \mu \mathrm{M}$, reaching the peak value at $48 \mathrm{~h}$. However, cells treated with $1 \mu \mathrm{M}$ MLN4924 were restrained at $\mathrm{S}$ phase (Figure 2b). MGC80-3 cells shared a similar cell cycle alteration at 0.1 and $0.3 \mu \mathrm{M}$ MLN4924. However, when MGC80-3 cells were treated with $1 \mu \mathrm{M}$, the proportion of $\mathrm{G} 2 / \mathrm{M}$-arrested cells 
reached the maximum more quickly at $24 \mathrm{~h}$ and then decreased over time, similar to the disappearance of the G2/M phase of AGS cells (Figure 2c).

P27 is well known for its functions in inhibiting CDK4/6Cyclin D complexes and CDK2-Cyclin E/A complexes and blocking the cell cycle transition from the $\mathrm{G} 1$ to $S$ phase. Therefore, although the treated cells were severely arrested in the G2/M phase instead of the G1 phase, we speculated that P27 promoted this cell cycle abnormality together with other cell cycle regulators.

P27 silencing enhanced the suppression effects of MLN4924 on gastric cancer cells. To elucidate the functions of P27 in MLN4924-induced inhibition of proliferation, we knocked down P27 expression using two different siRNA in treated gastric cancer cells and effectively confined P27 accumulation (Figure 3a, Supplementary Figures S2a and S3a). Surprisingly, instead of obstructing the MLN4924induced growth suppression, P27 silencing enhanced its cytotoxicity. As shown in the CCK8 assay, the cell viability of the combined treatment group was significantly lower than that of the group transfected with non-sense control sequence (NC) and treated by MLN4924 (Figure 3c, Supplementary Figure S3b). Similarly, in the colonyformation assay, the number of colonies in siP27-MLN4924 group was reduced by $17 \%$ compared with that of NCMLN4924 group, although the number of colonies in the siP27-DMSO group was just slightly decreased (Supplementary Figure S2b). The Live-dead cell staining also suggested impaired cell viability in the siP27-MLN4924 group (Figure 3b, Supplementary Figure S2c). Besides, a similar phenomenon was recorded in HepG2 cells, a hepatocellular carcinoma cell line (Supplementary Figures S4a and b). These data demonstrated the significant enhancement of MLN4924 cytotoxicity after downregulation of P27 in vitro.

Furthermore, to assess the combined effects of MLN4924 treatment and P27 knockdown in vivo, we transplanted AGSGFP (AGS cells expressing green fluorescent protein) which had been transfected with NC or siP27 into zebrafish embryos and incubated them with MLN4924. ${ }^{29,30}$ This newly emerged zebrafish xenograft model provided a more direct way to observe the tumor growth, which enabled us to accurately determine the benefit of P27 knockdown after MLN4924 treatment. $^{31-33}$ As shown in Figures $3 d$ and e, the average tumor sizes of the four groups, indicated by the lateral fluorescent areas, had the same discrepancy between each other as we observed in in vitro studies.

G2/M arrest and apoptosis induced by MLN4924 were augmented by siP27 in gastric cancer cells. Given the critical roles of P27 in the regulation of mitosis in human somatic cells, we initiated further cell cycle studies on the combined treatment groups. As shown in Figure 4a, G2/M arrest was strengthened in both AGS and MGC80-3 cells following simultaneous P27 silencing and MLN4924 treatment. This implied that P27 functioned as a protective factor against severe cell cycle abnormalities in these cells (Supplementary Figure S5). On the other hand, the sub-G1 proportions of the combined treatment group at $72 \mathrm{~h}$ rose to
1.8-2 times that of the NC-MLN4924 groups, suggesting that the increased cell death previously demonstrated was owing to enhanced apoptosis (Figure $4 \mathrm{a}$, right panel). The activation of cleaved caspase-3 and PARP further confirmed this notion (Figure 4b). Flow cytometry (FCM) for cleaved caspase-3 showed a $9-14 \%$ augmentation of caspase-3 activation in the combined treatment group (Figure 4c). On the basis of these results, we proposed that $\mathrm{P} 27$ protects gastric cancer cells from the MLN4924-induced growth suppression, and that its functional deficiency would lead to the amplification of MLN4924 cytotoxicity.

In addition, while caspase-8 activation was only slightly enhanced in AGS cells, the cleavage of caspase- 9 was increased in two combined treatment groups (Figure 4b, Supplementary Figure S3a). This discrepancy indicated that the intrinsic apoptotic pathway was the general mechanism for the enhanced apoptosis among different gastric cancer cell lines. ${ }^{34}$

P27 silencing strengthened MLN4924-induced ROS overproduction. Consistent with the intensive activation of caspase-3 and caspase- 9 after the combination treatment, Annexin V/propidium iodide staining of AGS and MGC80-3 cells indicated an upregulated proportion of cells proceeding through apoptosis (Figure 5a, Supplementary Figures S6a and S7a). In previous works, MLN4924 has been shown to induce ROS overproduction in myeloid leukemia cells, which is tightly connected with the intrinsic apoptotic pathways. ${ }^{26}$ To determine whether ROS overproduction might be the central event for the augmented cytotoxicity caused by P27 silencing in the MLN4924 treatment, we used the fluorescent probe DCFH-DA to measure the ROS levels of the four groups at $24 \mathrm{~h}$. ROS generation in groups treated with only MLN4924 was significantly higher than in the control groups, but it reached the highest level in the combined treatment groups (Figure 5b, Supplementary Figures S6b and S7b). As the antioxidant $\mathrm{N}$-acetyl cysteine (NAC) ubiquitously suppressed ROS generation in the MLN4924-treated cells, MitoTEMPO (a specific scavenger of mitochondrial superoxide) exerted similar effects, suggesting mitochondria should be the major source of the accumulated ROS. In particular, ROS levels in the combined treatment groups were reduced to a comparable degree of those in the NC-MLN4924 groups. This reduction conferred an apparent resistance to the enhanced cytotoxicity in the gastric cancer cells and rescued them from excessive apoptosis (Figure 5a, Supplementary Figure S7a). The fact that NAC and MitoTEMPO shared similar protective effects toward the ROS-triggered apoptosis despite their different cellular compartment specificity emphasized the importance of mitochondria in enhanced apoptosis in the combined treatment groups.

Enhanced exportation of apoptosis-related proteins from the mitochondria to the cytoplasm. Mitochondria are critical to basic cellular functions, and their dysregulation leads to disorders of respiration and energy supply which would guide cells to programmed death. Numerous substances inside the mitochondria need escape into the cytoplasm to trigger the downstream signals of apoptosis, 
a

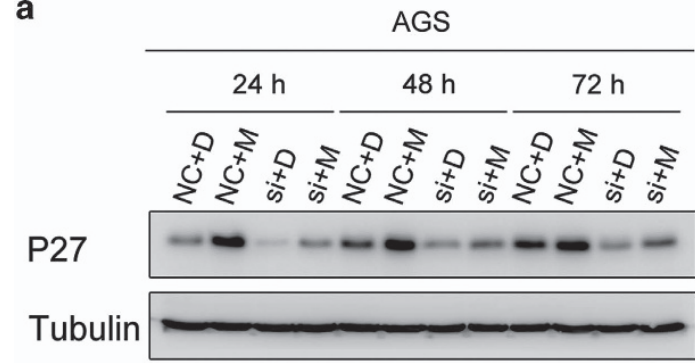

b
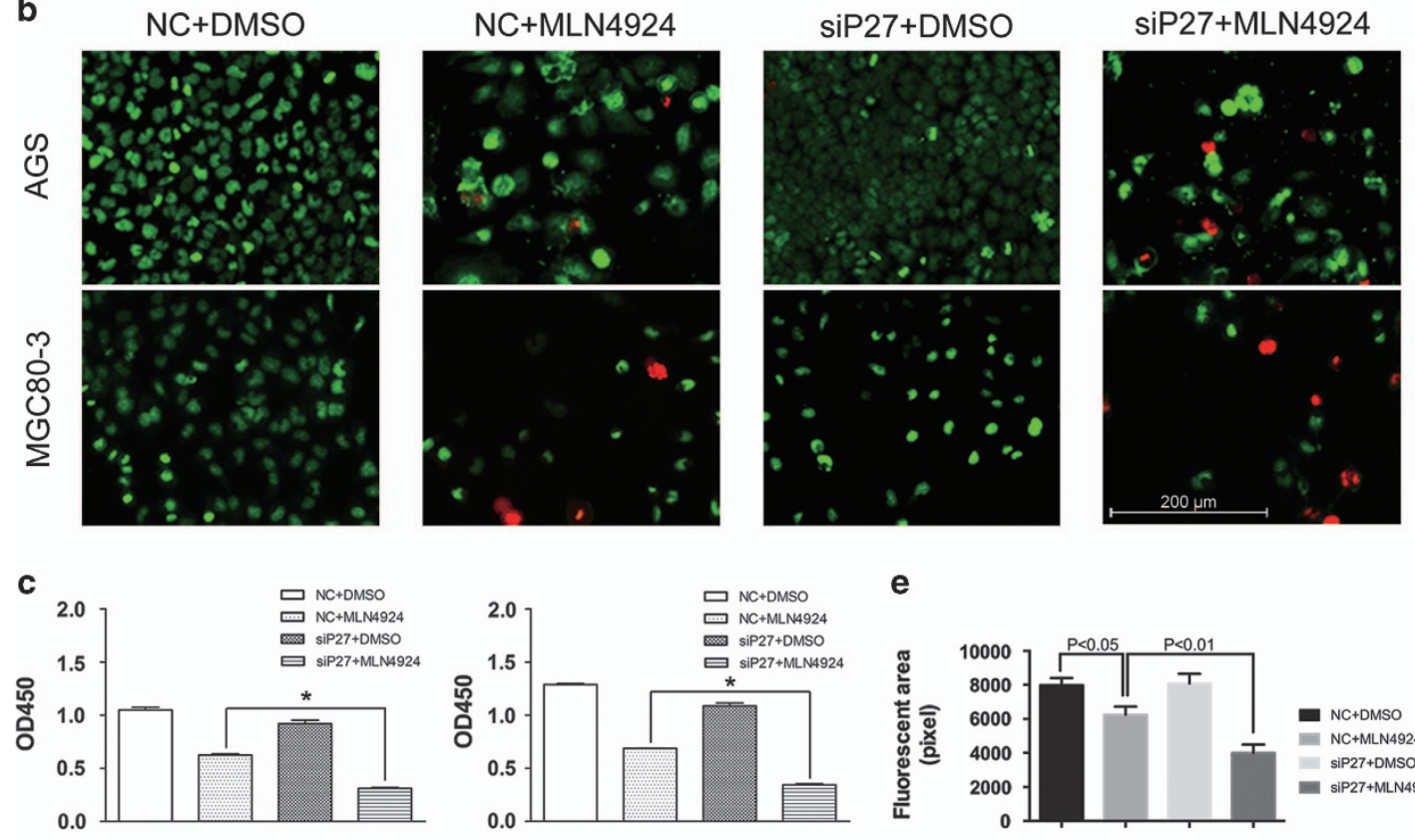

e

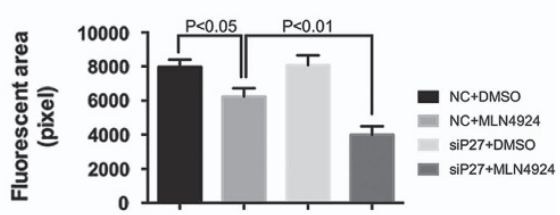

d

AGS-GFP
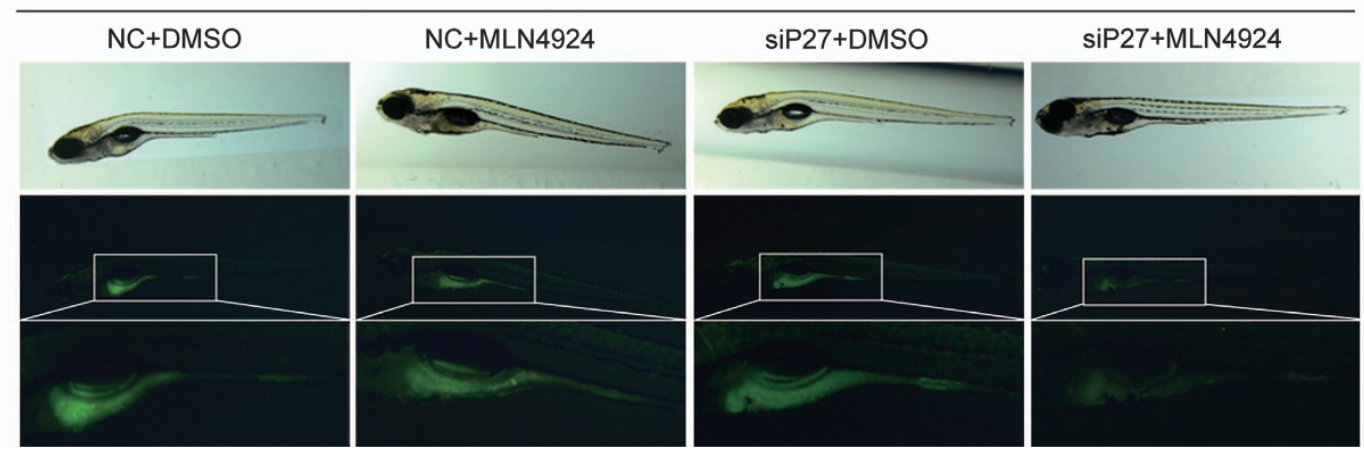

Figure 3 P27 silencing enhanced the cytotoxicity of MLN4924 in gastric cancer cells. (a) The designed siRNA downregulated P27 in gastric cancer cells. AGS and MGC80-3 cells were transfected with NC or siP27 for $72 \mathrm{~h}$ and then subjected to immunoblotting analysis for expression of P27 and tubulin. (b and c) SiP27 enhanced the cytotoxicity of MLN4924 in gastric cancer cells. AGS and MGC80-3 cells transfected with NC or siP27 were treated with DMSO or $0.3 \mu$ M MLN4924. Cells were then subjected to stained by Live Dye (green) and propidium iodide (red) in vivo (bottom panel), or the CCK8 colorimetric assay (top panel). The dead cells (b) were indicated by red. (d) Smaller tumor size after combination treatment of the zebrafish xenograft models for AGS-GFP. AGS cells with GFP fluorescence transfected with NC or siP27 were transplanted into zebrafish embryos. Tumor sizes were indicated by the lateral fluorescent area. For panel $\mathbf{b}, n=4$; for panel $\mathbf{d}, n=10$. NC= Non-sense control siRNA; $D=D M S O ; M=M L N 4924$; $\mathrm{si}=$ siRNA for P27

such as caspase family activation and IAP family inhibition. $^{35,36}$

We isolated mitochondria and cytoplasm from AGS and MGC80-3 cells to examine the export of three representative substances from mitochondria: apoptosis-inducing factor
(AIF), IAP-binding mitochondrial protein (SMAC/DIABLO) and cytochrome c. As shown in Figure 6, at $24 \mathrm{~h}$, AIF and SMAC/DIABLO did not redistribute between the two fractions in either cell line. However, cytochrome $c$ in the combined treatment groups, the primary activator of caspase cascades, 

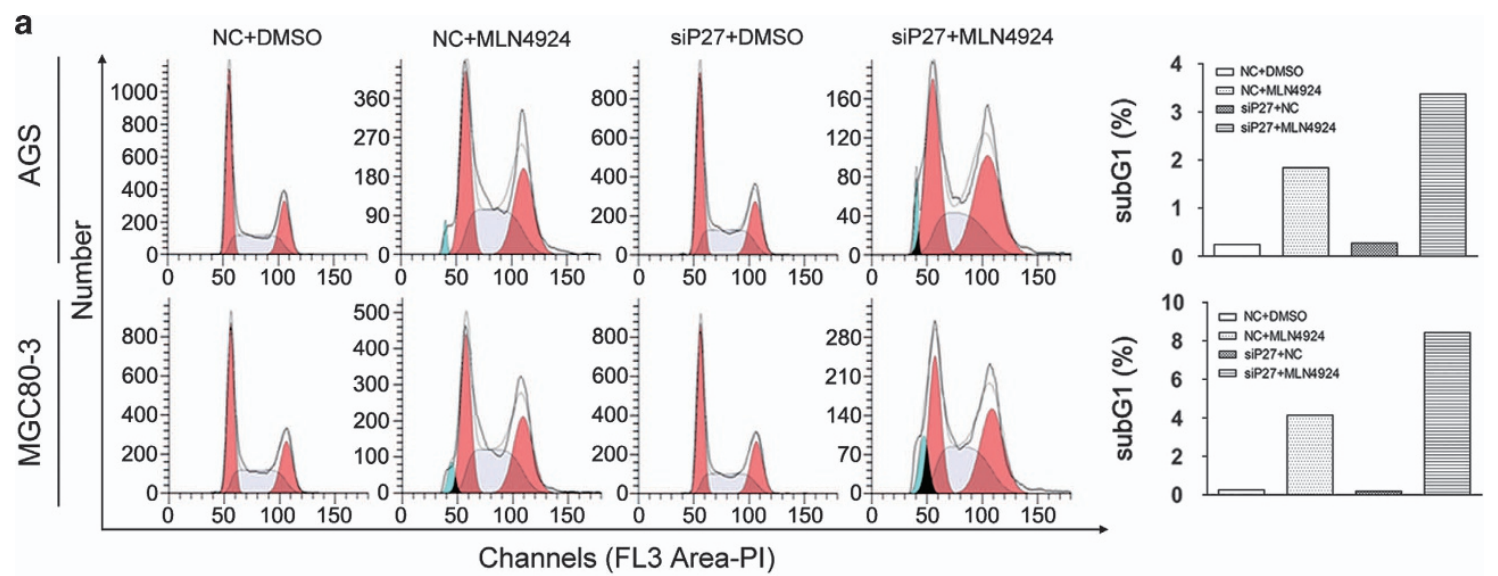

b
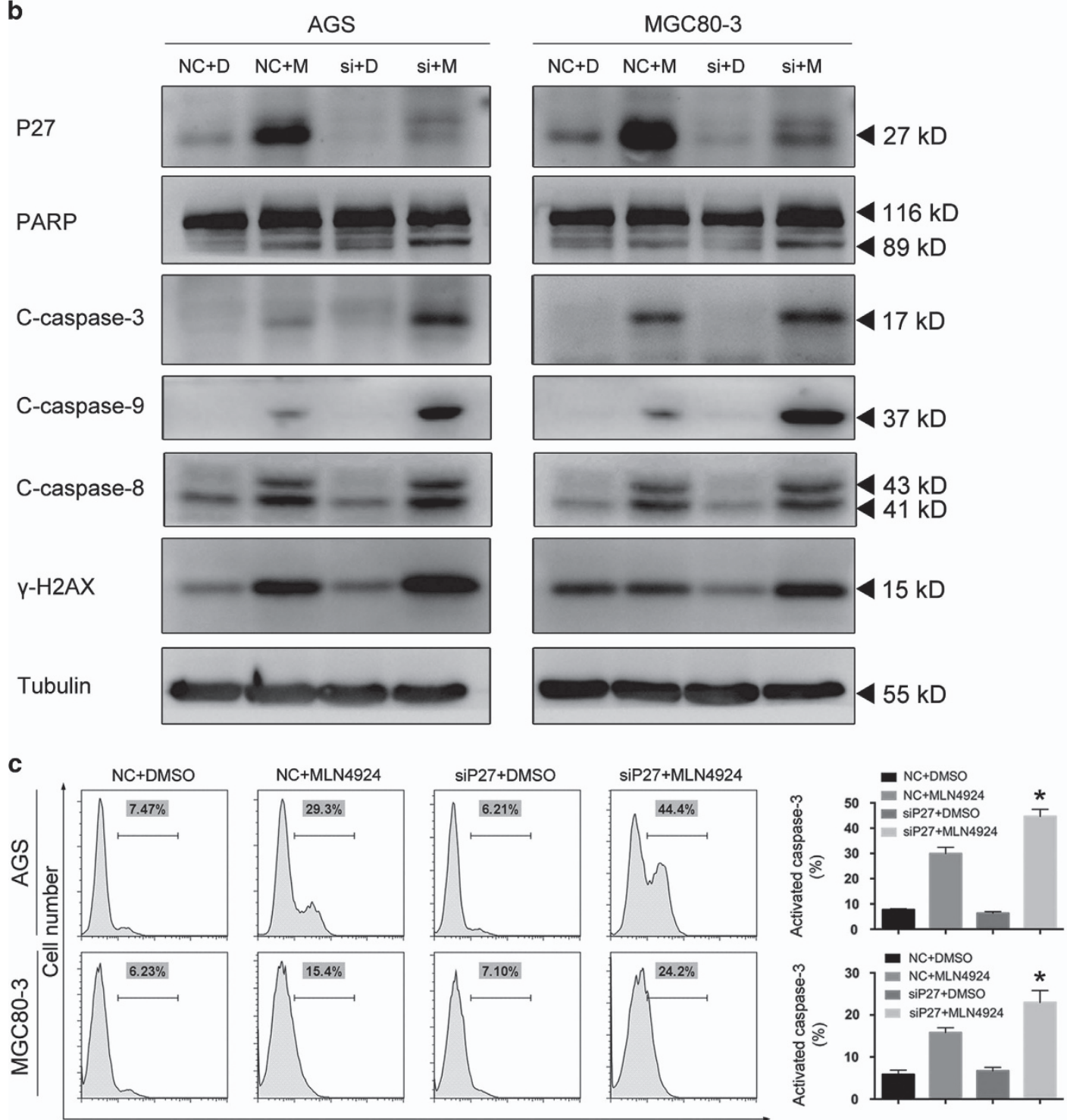

FL1 FITC 
displayed a mild export into the cytoplasm. At $48 \mathrm{~h}$ in the AGS cells, higher levels of SMAC/Diablo and cytochrome $\mathrm{c}$ in this group were found in the cytoplasm. In contrast, only slight changes in cytochrome c were observed in the NC-MLN4924 group. In the MGC80-3 cells, only cytochrome c was exported into the cytoplasm after the MLN4924 treatment, indicating that apoptosis was initiated by P27 downregulation. In MGC80-3 cells, all three proteins including AIF had a significant escape from the intermembrane space of the mitochondrial membranes into the cytoplasm at $72 \mathrm{~h}$. These results demonstrated that the synergistic effects of siP27 and MLN4924 were mediated by the typical intrinsic apoptotic pathway. The mitochondrion is the most pivotal compartment in this process, which connects the upstream signals from ROS overproduction with the following activation of executors for the apoptosis.

P27 silencing deregulated mitochondrial membrane permeability by modulating the BCL-2 family. Under normal conditions, the permeability of the outer and inner membranes is critical for maintaining mitochondrial membrane potential (MMP). However, when cells undergo programmed cell death, the mitochondrial apoptosis-induced channels (MAC) are assembled and facilitate the export of cytochrome c, SMAC/DIABLO and AIF to activate their cytosolic effectors with the inevitable loss of MMP. ${ }^{37,38}$

In both gastric cancer cell lines treated with MLN4924, the proportions of cells undergoing the MMP collapse were significantly increased (Supplementary Figure S8). Meanwhile, the loss of MMP in the treated cells with lowered P27 expression was approximately $8-13 \%$ higher than that in the NC-MLN4924 groups (Figure 7a). Similarly, the Annexin $\mathrm{V} /$ propidium iodide staining showed that pre-incubation with NAC or MitoTEMPO was capable of rescuing cells from this augmentation (Figure 5a). This observation suggested that P27 silencing induced ROS overproduction and thus triggered MAC assembly and implied the robust ROS production might either recruit the key components of MAC from the pro-apoptotic BCL-2 family or repress their regulators from the anti-apoptotic BCL-2 family.

Western blotting demonstrated that several members from the pro-apoptotic BCL-2 family were upregulated in the MLN4924-treated groups, including BIM, BID and BAD (Figure $7 \mathrm{~b}$ ). Moreover, the expression of BCL-2, BCL-XL and MCL-1, which belong to the anti-apoptotic BCL-2 family were strongly increased in the combined treatment groups. The phosphorylation of BCL-2 was also significantly augmented. This posttranscriptional modification has been reported to promote cellular survival under ROS overproduction crisis. In contrast, expression of $\mathrm{MCL}-1$ in the combined treatment groups remarkably decreased while BCL-XL was unaffected compared with the NC-MLN4924 groups. As for BCL-2, paradoxical changes of its protein level and phosphorylation state were observed in both cell lines. While its protein level was significantly increased, the phosphorylation of BCL-2, which is closely connected with P27 overexpression and ROS suppression, was severely reduced to the basal level. ${ }^{39}$ Correspondingly, in the pro-apoptotic family, the activation of BIM was further enhanced, even though the protein levels of BID and BAD were reduced. Most importantly, silencing P27 during MLN4924 treatment induced an unexpected cleavage of BAX into p18-BAX. This transformation of BAX has been reported to enable itself to avoid the $B C L-2$ inhibitory functions and directly construct MAC. ${ }^{40}$

Therefore, we concluded that P27 silencing in the MLN4924treated cells activated the assembly of MAC components via ROS overproduction and further suppressed the major inhibitors by interfering with their protein levels, blocking their phosphorylation or directly sequestering them, thus strengthening the apoptotic signals in the gastric cancer cells.

\section{Discussion}

As a critical regulator of cell cycle progression, P27 has been considered to be a tumor-suppressor gene in the conventional view. It is degraded by the SCF-complex-mediated ubiquitinproteasome system. However, the functions of P27 as an important ubiquitin E3 ligase substrate remain unclear. In this study, we provided new insights into the functions of p27, which suggested that $\mathrm{p} 27$ inhibition could be considered as a potential treatment for cancer, particularly in combination with MLN4924.

When cells are preserved in the quiescent state, P27 is upregulated to block uncontrolled cell cycle progression. By induced fit, P27 can bind with the three different CDK-Cyclin complexes, CDK4/6-CyclinD, CDK2-CyclinE/A and CDK1CyclinB, and impede their kinase activities. Thereby, P27 suppresses the major facilitators of the G1/S transition and prevents the cell cycle from entering subsequent phases. In our study, the discrepancy between cell cycle arrest at different concentration of MLN4924 suggests that P27 coordinated with other regulators to determine cell cycle progression. When P27 expression was silenced first, the proportion of G2/M-arrested cells, which should have reached the peak value with $0.3 \mu \mathrm{M}$ MLN4924 treatment, strikingly increased without additional drugs. This finding is in accordance with previous studies about the central position of P27 in the regulation of the $\mathrm{G} 1$ phase $^{11}$ and implies that it has protective potential for gastric cancer cells. Intriguingly, we also established the improved efficacy of MLN4924 by P27 knockdown in in vivo studies based on the zebrafish xenograft model, ${ }^{29,33}$ and found this sensitization by P27 silencing might be applied in other cancers as well (Supplementary Figure S4). These discoveries provided the proof-of-concept evidences for the application of P27 inhibition in cancer treatment, especially with MLN4924.

Figure 4 Intrinsic apoptotic signals induced by MLN4924 were strengthened by P27 silencing in gastric cancer cells. AGS and MGC80-3 cells transfected with NC or siP27 were treated with DMSO or $0.3 \mu \mathrm{M}$ MLN4924 for $72 \mathrm{~h}$. (a) Sub-G1 accumulation following combination treatment. Cells were subjected to propidium iodide staining and FCM for analysis of cell cycle profile. (b) Expression of apoptotic proteins following combination treatment. Cells were subjected to immunoblotting analysis of the expression of the indicated proteins. (c) Enhanced caspase-3 cleavage by P27 silencing in MLN4924-treated cells. Cells were subjected to FITC-DEVD-FMK staining and FCM for cleaved caspase-3 quantification. For panel $\mathbf{c}, n=3 . \mathrm{NC}=$ Non-sense control siRNA; $\mathrm{D}=\mathrm{DMSO} ; \mathrm{M}=\mathrm{MLN4924;}$ si = siRNA for P27 

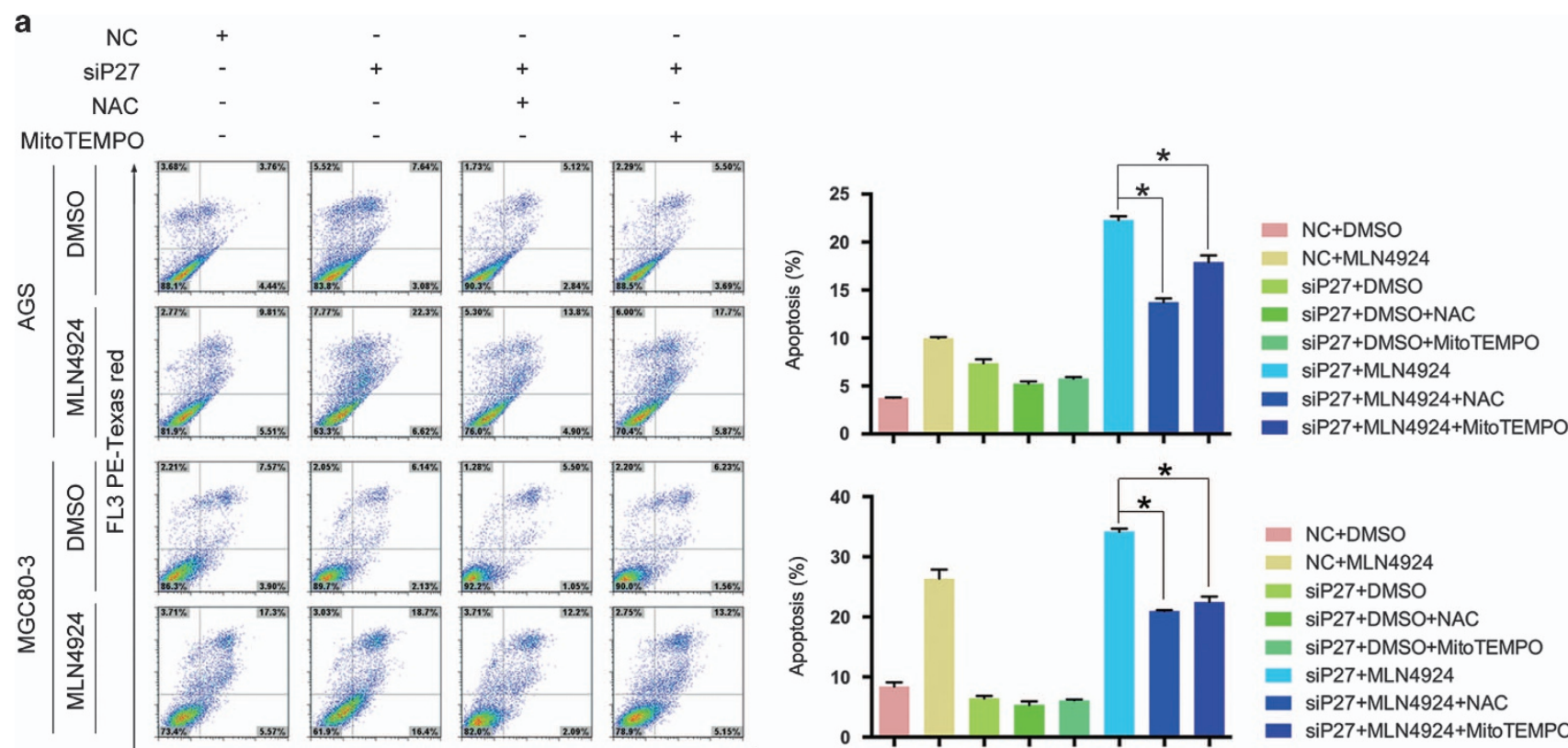

FL1 FITC

$\begin{array}{rr}\text { DMSO } & + \\ \text { MLN4924 } & - \\ \text { NC } & + \\ \text { SiP27 } & - \\ \text { NAC } & -\end{array}$

MitoTEMPO -

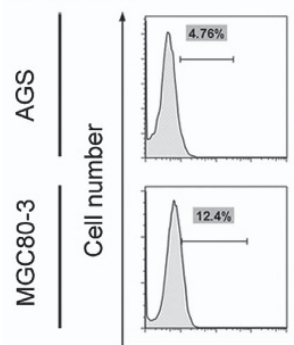

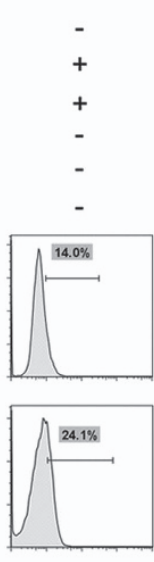

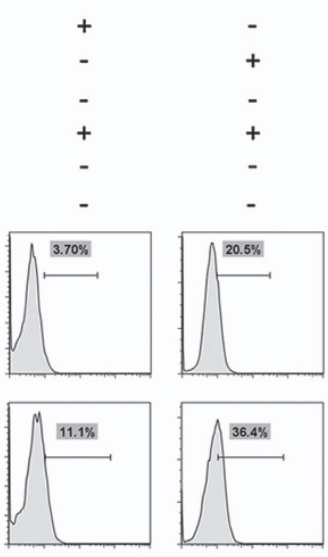

FL1 FITC

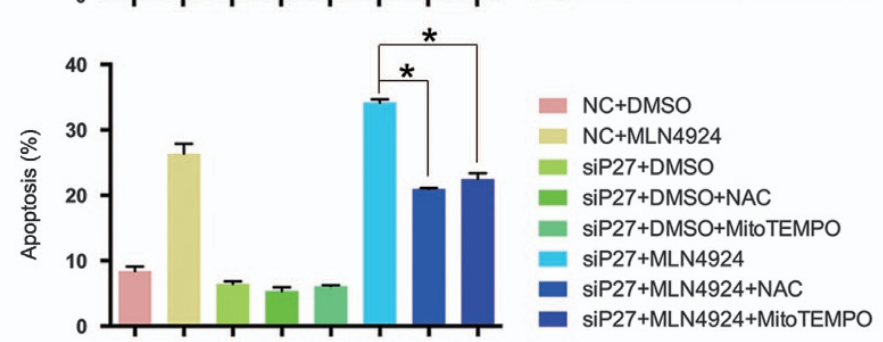

Figure 5 ROS overproduction following combination treatment resulted in augmented apoptosis. AGS and MGC80-3 cells transfected with NC or siP27 were treated under the indicated combination of MLN4924 and antioxidants. (a) The siP27-induced apoptosis augmentation in MLN4924-treated gastric cancer cells. The apoptosis was determined by Annexin V/propidium iodide double staining and FCM. (b) P27 silencing exacerbated ROS overproduction in MLN4924-treated cells. ROS levels were quantified by DCFH-DA staining and FCM. For panel $\mathbf{a}$ and $\mathbf{b}, n=3$

As an important initiator for MAC component activation, ${ }^{41}$ ROS overproduction has been detected previously in MLN4924-treated leukemia cells in others' studies. ${ }^{28}$ In this work, after silencing P27, the MLN4924-treated cells underwent increased ROS generation together with an augmented MMP collapse and apoptosis. The NAC's antagonism to this cytotoxicity sensitization explicitly verified ROS as the initiator in P27-related apoptotic signal pathways. A similar effect of MitoTEMPO, the mitochondrion-specific ROS scavenger, indicated that the mitochondria were the major source of the excessive ROS production in the MLN4924-treated cells with lower P27. In addition, the simultaneous translocation of cytochrome c, SMAC/DIABLO and AIF in the combined treatment groups (Figure 6) also emphasized the critical role of mitochondria for cytotoxicity sensitization of MLN4924 and indicated that the assembly of MAC might be the pivotal process that connected P27 with the downstream signals for apoptosis.

Conforming to previous reports that robust ROS production activates the mitochondrial outer membrane pore assembly, the protein pattern shift of BCL-2 family members was observed after P27 knockdown in treated gastric cancer cells. In MLN4924-treated cells, the anti-apoptotic family members were significantly upregulated, while BAK and BAX, the major components of MAC, remained unchanged. In contrast, after P27 knockdown, the MCL-1, BCL-2 phosphorylation, BAX cleavage and BIM in the treated cells behaved synergic to augment apoptosis (Figure 7b). BCL-2 phosphorylation has been shown to upregulate P27 and resist intracellular ROS-induced damages in the previous study. However, our 

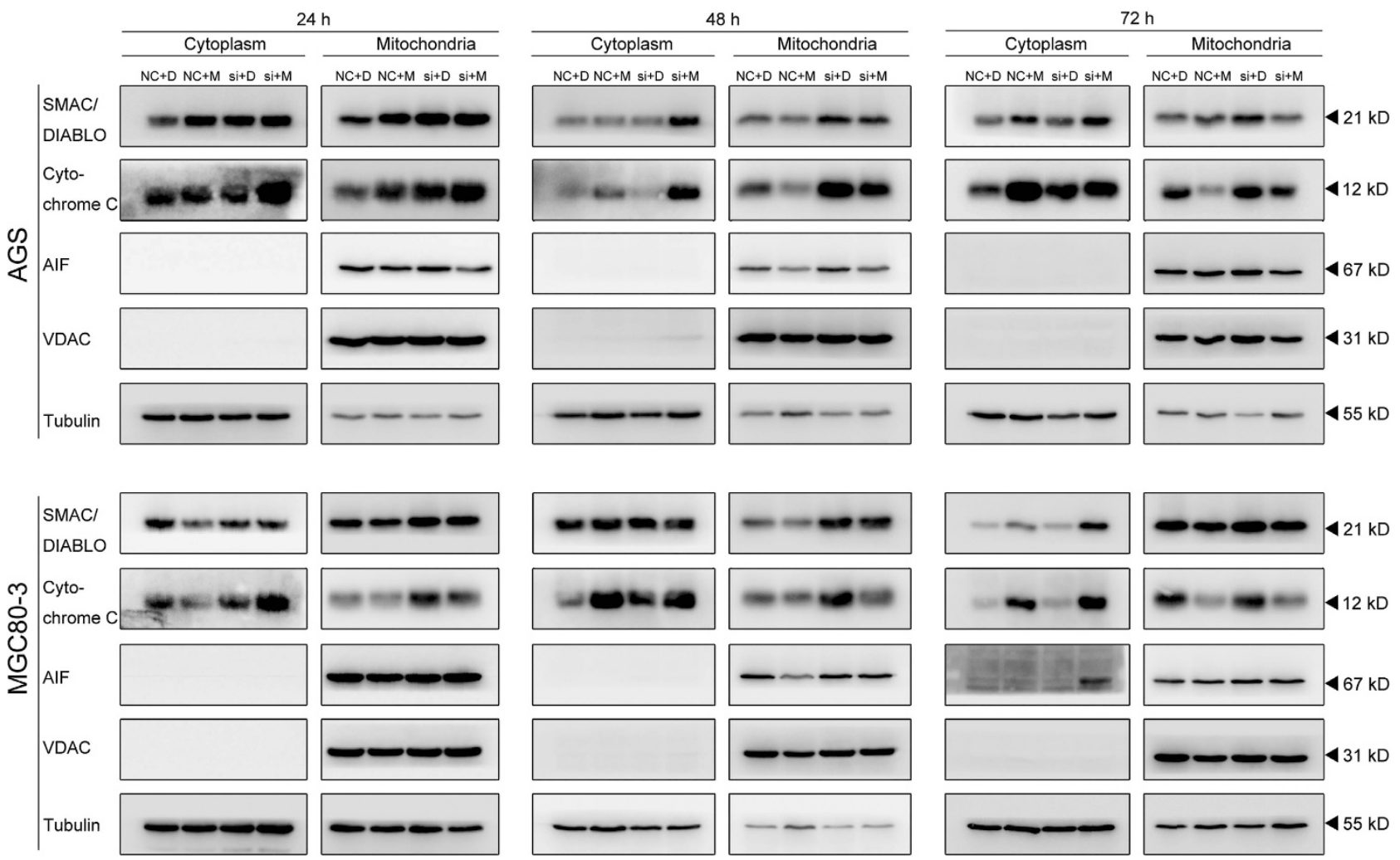

Figure 6 Translocation of apoptosis-related molecules from the mitochondrial intermembrane space to the cytoplasm in siP27-transfected gastric cancer cells. AGS and

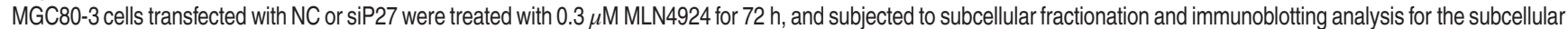
localization of indicated proteins

results suggested that $\mathrm{P} 27$ was also able to induce the $\mathrm{BCL}-2$ phosphorylation for apoptotic resistance, which therefore revealed a mutual activation between P27 and BCL-2 phosphorylation for cell survival. As for BAX cleavage, it was mediated by the calcium-dependent protease calpain and resulted in the formation of p18-BAX, which was not subjected to inhibition by BCL-2. ${ }^{40,42,43}$ As calpain is the key executor of the non-ubiquitin degradation of P27 in the cytoplasm, ${ }^{44}$ P27 that accumulated after MLN4924 treatment might protect cells from the uncontrolled p18-BAX by saturating the enzymatic activity of calpains.

In previous studies, the sub-cellular translocation of P27 with different phosphorylation status was regarded as the decisive point for the susceptible dual roles of P27 in tumorigenesis. The threonine-187-phosphorylated (T187phosphorylated) P27 is the candidate substrate for $\mathrm{SCF}^{\mathrm{SKP} 2}$-mediated proteasome degradation in the nucleus, while the phosphorylation at threonine-157, threonine-198 and serine-10 targets P27 into the cytoplasm and impairs the function of its nuclear localization sequence, ${ }^{45-47}$ providing the basis for its cytoplasmic degradation by the Kip1 ubiquitination-promoting complex (KPC) and calpain. In theory, SCF ${ }^{\text {SKP2 }}$ inhibition by MLN4924 should lead to the accumulation of T187-phosphorylated P27, which is restricted in the nucleus. This deduction contradicted the apoptotic signals that emerged in our study that required the direct interaction of P27 in the cytoplasm, such as the ROS overproduction and BAX cleavage. Because the two types of phosphorylation mainly decide the sub-cellular localization of P27 and are inconvertible to each other, we assumed that there must be a recycling mechanism that relieves T187 phosphorylation of P27 and prepares it for cytoplasm-targeted phosphorylation by other kinases, such as AKT and MEK. Further analysis, as well as more specific interfering methods for the different phosphorylation events, are necessary to test this assumption.

Even though several studies have reported a susceptible oncogenic character of P27 in tumors treated by preussin or proteasome inhibitors, they have not clarified the underlying mechanism. ${ }^{48-50}$ Our study for the first time revealed P27 functioned as a protective protein for tumor cells by suppressing ROS generation, modulating the profile of BCL-2 family members and maintaining the normal mitochondrial status in gastric cancer cells treated with MLN4924. In addition, the remarkable sensitization of MLN4924 by P27 silencing revealed in our study indicates that there is a potential of combining MLN4924 with P27 inhibitors to improve its therapeutic efficacy.

\section{Materials and Methods}

Cell culture and reagents. The human gastric cancer cell lines AGS and MGC80-3 were obtained from the Type Culture Collection of the Chinese Academy of Sciences (Shanghai, China). These cells were cultured in Dulbecco's modified Eagle's medium (Gibco, Life Technologies, Carlsbad, CA, USA) containing 10\% fetal bovine serum and $1 \%$ penicillin-streptomycin at $37^{\circ} \mathrm{C}$ with $5 \% \mathrm{CO}_{2}$. MLN4924 was purchased from Millennium (Cambridge, MA, USA). For in vitro studies, MLN4924 
a

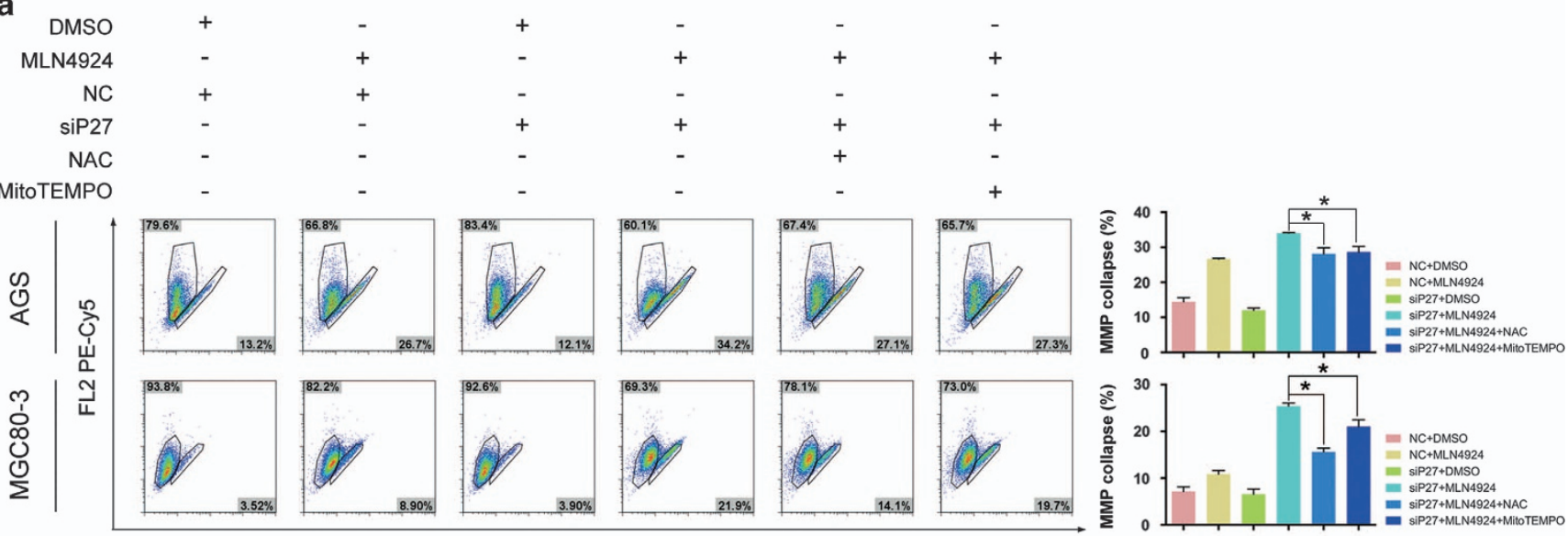

FL1 FITC

b
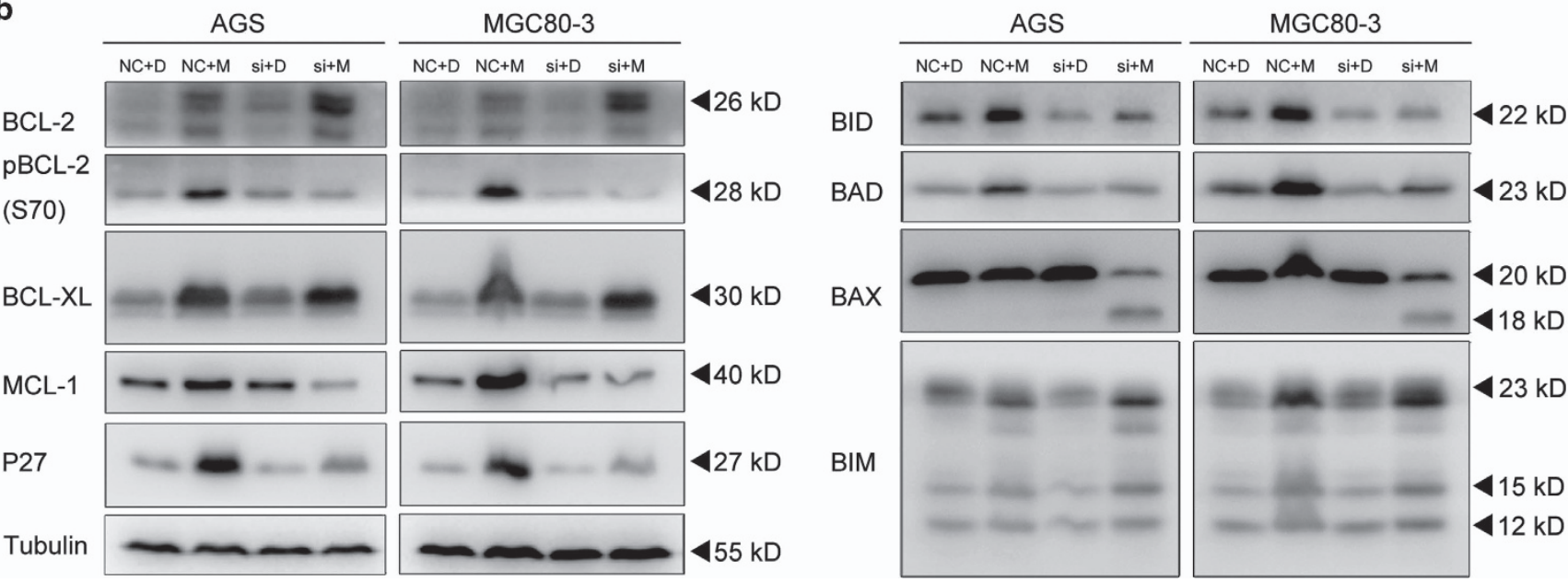

Figure 7 ROS triggered the collapse of MMP via siP27-induced profile alteration of BCL-2 family members in MLN4924-treated cells. (a) Deterioration of MMP collapse in the MLN4924-treated cells expressing low P27 was prevented by antioxidants. AGS and MGC80-3 cells transfected with NC or siP27 were treated under the combination of MLN4924 and antioxidants for $72 \mathrm{~h}$, and subjected to JC-1 staining and FCM for the determination of MMP collapse. (b) P27 silencing led to alteration of BCL-2 family members expression in MLN4924-treated cells. AGS and MGC80-3 cells transfected with NC or siP27 were treated with $0.3 \mu \mathrm{M}$ MLN4924 for $72 \mathrm{~h}$, and subjected to immunoblotting analysis for the detection of expression and status of indicated proteins. For panel $\mathbf{a}, n=3$

was stored at a concentration of $10 \mu \mathrm{M}$ at $-20^{\circ} \mathrm{C}$. NAC and MitoTEMPO were purchased from Sigma (St. Louis, MO, USA).

Immunoblotting. Cell lysates were extracted with cell lysis buffer (Beyotime Biotechnology, Nantong, China), and the protein concentration in the lysates was quantified using a Micro BCA Protein Assay Kit (Sangon Biotech, Shanghai, China). A total of $20-50 \mu \mathrm{g}$ of each cell lysate sample was loaded for immunoblotting and detected by antibodies that recognize Tubulin, VDAC, AIF, SMAC/DIABLO, cytochrome c (Epitomics, Hangzhou, China), CUL1 (Santa Cruz Biotechnology, Santa Cruz, CA, USA), CDKN1B/P27, CDKN2A/P16, PARP, $\gamma H$ 2AX, caspase3, caspase8, caspase9, BCL-2, pBCL-2 (S70), BCL-XL, MCL-1, BID, BAD, BAX, and BIM (Cell Signaling Inc., Danvers, MA, USA).

RNA interference. siRNA oligonucleotides were synthesized by GenePharma (Shanghai, China) and were transfected into gastric cancer cells by Lipofectamine 2000 (Invitrogen, Carlsbad, CA, USA). Briefly, siRNA and Lipofectamine 2000 were incubated separately with Opti-MEM (Invitrogen, Carlsbad, CA, USA) for $5 \mathrm{~min}$ and then mixed together for $20 \mathrm{~min}$ at room temperature. The mixture was then applied to the cells plated in $60-\mathrm{mm}$ dishes (final concentration of siRNA is $50 \mathrm{nM}$ ). The sequence of the siRNA for CDKN1B/P27 (siP27) was 5'-GCAACCGACGAUUCUU CUATT-3'. The scrambled siRNA control (siControl) sequence was $5^{\prime}$-TTCTCCG AACGTGTCACGTTT-3'.
Propidium iodide staining and FACS analysis. For cell cycle distribution and apoptosis analysis, cells were harvested and fixed in $70 \%$ ethanol at $-20^{\circ} \mathrm{C}$ overnight. They were then incubated with the staining buffer containing $36 \mu \mathrm{g} / \mathrm{ml}$ propidium iodide (Sigma) and $400 \mu \mathrm{g} / \mathrm{ml}$ RNase (Roche, Mannhein, Germany) at $37^{\circ} \mathrm{C}$ for $20 \mathrm{~min}$ and analyzed by FCM (CyAnTM ADP, Beckman Coulter, Brea, CA, USA). Data were analyzed with ModFit LT software (Verity Software House, Topsham, ME, USA).

SA- $\beta$-galactosidase staining. Intact cells or those transfected with siP27 for $24 \mathrm{~h}$ were split and seeded into 12-well plates at 10000 cells per well and then evaluated by SA- $\beta$-gal staining as described previously. ${ }^{51}$

Cell proliferation and colony-formation assay. Cells were either seeded into 24-well plates at 6000 cells per well in triplicate for cell counting at indicated time points, or they were seeded into 96-well plates at 1000 cells per well in quadruplicate for the CCK8 colorimetric assay (Dojindo, Kumamoto, Japan) according to the manufacturer's specifications. For the colony-formation assay, the split cells were seeded into 6-well plates (500 cells per well) and cultured for 10 days. The colonies on the plates were fixed with $4 \%$ paraformaldehyde and then stained with crystal violet.

Viability staining. The P27-silenced cells were seeded into 24-well plates at 10000 cells per well and incubated with DMSO or $0.3 \mu \mathrm{Mol} / \mathrm{l}$ MLN4924 for $72 \mathrm{~h}$. 
They were then washed with PBS and incubated with $500 \mu l$ staining buffer containing $0.5 \mu \mathrm{l}$ Live Dye (Enzo Life Sciences, Farmingdale, NY, USA) and $0.5 \mu$ propidium iodide (2.5 mg/ml, Enzo Life Sciences) for $20 \mathrm{~min}$ in a $37^{\circ} \mathrm{C}$ incubator with $5 \% \mathrm{CO}_{2}$. The cells were photographed under a fluorescence microscope (Leica, Wetzlar, Germany).

Establishment of AGS-GFP stable cell lines. AGS cells expressing GFP were established as described. Briefly, cells were seeded in 100-mm dishes and transfected with the lentivirus containing GFP DNA. Cells with GFP fluorescence were selected by MoFlo XDP Cell Sorter (Beckman Coulter) and cultured in complete cell culture medium containing puromycin (Beyotime Biotechnology) at $0.5 \mu \mathrm{g} / \mathrm{ml}$.

Zebrafish xenograft model. The fertilized wild-type $A B$ zebrafish eggs were collected and incubated at $29^{\circ} \mathrm{C}$ in E3 embryo medium for $48 \mathrm{~h}$. At 48 h.p.f. (hour post fertilization), the chorion were removed by forceps. The embryos were then treated with $0.02 \mathrm{mg} / \mathrm{ml}$ tricaine (Sigma) before receiving microinjection of cancer cells with GFP. One hundred and fifty cells transfected with NC or siP27 were transplanted into the space between the periderm and the yolk syncytial layer. Thirty injected embryos were incubated with $1 \mu \mathrm{M}$ MLN4924 diluted in E3 embryo medium for $96 \mathrm{~h}$. Ten zebrafishes were randomly selected and photographed under a fluorescence microscope (Leica). The lateral fluorescent area indicating the size of the tumor mass was calculated and analyzed by ImageJ software.

Quantification of cleaved caspase-3. To measure caspase-3 cleavage, cells were harvested and incubated with the FITC-DEVD-FMK (BioVision, Milpitas, CA, USA) in PBS in a $37^{\circ} \mathrm{C}$ incubator with $5 \% \mathrm{CO}_{2}$ for $30 \mathrm{~min}$. Samples were centrifuged at 3000 r.p.m., and the supernatant was removed. The cells were resuspended in wash buffer and centrifuged twice. Cells were re-suspended in PBS, and caspase- 3 cleavage was analyzed by FCM.

Detection of ROS and measurement of MMP. For the ROS detection, cells were harvested and mixed with $10 \mu \mathrm{M}$ DCFH-DA (Beyotime Biotechnology) diluted in PBS at $37^{\circ} \mathrm{C}$ for $20 \mathrm{~min}$. For the positive control groups, cells were incubated with $0.05 \mathrm{mg} / \mathrm{ml}$ Rosup for $20 \mathrm{~min}$ first and then with DCFH-DA. Cells were washed twice, followed by analysis by FCM. The same method was also applied to mitochondria potential monitoring with the probe JC-1 (Beyotime Biotechnology) and the positive control groups were incubated with $10 \mu \mathrm{M} \mathrm{CCCP}$ instead. Green $(510-530 \mathrm{~nm})$ and Red $(650 \mathrm{~nm})$ fluorescence emission from cells was measured following excitation at $488 \mathrm{~nm}$.

Mitochondria isolation. Gastric cancer cells were trypsinized, and washed by PBS. The cell suspension was centrifuged at $600 \times g$ at $4^{\circ} \mathrm{C}$ for $5 \mathrm{~min}$ and the supernatant was discarded. The mitochondria isolation medium (Beyotime Biotechnology) containing $1 \mu \mathrm{M}$ PMSF was then added to re-suspend the cell pellets in proportions of $1 \mu \mathrm{l}$ per $10^{4}$ cells. The cells were homogenized, and the supernatant was retained following a $10 \mathrm{~min} 600 \times \mathrm{g}$ centrifugation at $4^{\circ} \mathrm{C}$. The precipitate of mitochondria was isolated after $11000 \times g$ centrifugation for $10 \mathrm{~min}$. The supernatant were again centrifuged at $12000 \times \mathrm{g}$ for $10 \mathrm{~min}$. After discarding the precipitate, the leftover was preserved as the cytoplasm protein sample.

Statistical analysis. The statistical significance of differences between groups was assessed using GraphPad Prism5 software. The unpaired two-tailed $T$ test was used for the comparison of parameters between two groups. For all the tests, three levels of significance $(P<0.05, P<0.01$ and $P<0.001)$ were used. ${ }^{*} P<0.01$.

\section{Conflict of Interest}

The authors declare no conflict interest.

Acknowledgements. This work was supported by the grants from the National Natural Science Foundation of China (Nos. 81125001, 81372652 and 81201895) and One Hundred Person Project of the Shanghai Health (XBR2013117).

\section{Author contributions}

Study concept and design: Dongqin Yang; Acquisition of data: Qi Zhang, Daisen Hou and Fuchen Liu; Analysis and interpretation of data: Zhongguang Luo, Ping Chen and Hui Liu; Drafting of the manuscript: Qi Zhang and Dongqin Yang; Statistical analysis:
Bin Lv, Lijun Wu and Yunfang Ma; Critical revision of the manuscript for important intellectual content: Yiwei Chu; Material support: Shunji Yu and Jun Zhang; Study supervision: Jie Liu.

1. Ferlay J, Soerjomataram I, Dikshit R, Eser S, Mathers C, Rebelo M et al. Cancer incidence and mortality worldwide: Sources, methods and major patterns in GLOBOCAN 2012. Int J Cancer 2015; 136: E359-E386.

2. Masuda TA, Inoue $H$, Sonoda $H$, Mine S, Yoshikawa $Y$, Nakayama $K$ et al. Clinical and biological significance of S-phase kinase-associated protein 2 (Skp2) gene expression in gastric carcinoma: modulation of malignant phenotype by Skp2 overexpression, possibly via p27 proteolysis. Cancer Res 2002; 62: 3819-3825.

3. Bai J, Zhou Y, Chen G, Zeng J, Ding J, Tan Y et al. Overexpression of Cullin1 is associated with poor prognosis of patients with gastric cancer. Hum Pathol 2011; 42: 375-383.

4. Wei Z, Jiang X, Liu F, Qiao H, Zhou B, Zhai B et al. Downregulation of Skp2 inhibits the growth and metastasis of gastric cancer cells in vitro and in vivo. Tumour Biol 2013; 34: 181-192.

5. Soucy TA, Smith PG, Milhollen MA, Berger AJ, Gavin JM, Adhikari S et al. An inhibitor of NEDD8-activating enzyme as a new approach to treat cancer. Nature 2009; 458: U732-U67.

6. Tsvetkov LM, Yeh KH, Lee SJ, Sun H, Zhang H. p27(Kip1) ubiquitination and degradation is regulated by the SCF(Skp2) complex through phosphorylated Thr187 in p27. Curr Biol 1999; 9: $661-664$.

7. Carrano AC, Eytan E, Hershko A, Pagano M. SKP2 is required for ubiquitin-mediated degradation of the CDK inhibitor p27. Nat Cell Biol 1999; 1: 193-199.

8. Morimoto M, Nishida T, Honda R, Yasuda H. Modification of cullin-1 by ubiquitin-like protein Nedd8 enhances the activity of SCF(skp2) toward p27(kip1). Biochem Biophys Res Commun 2000; 270: 1093-1096.

9. Polyak K, Lee MH, Erdjument-Bromage $\mathrm{H}$, Koff A, Roberts JM, Tempst $\mathrm{P}$ et al. Cloning of p27Kip1, a cyclin-dependent kinase inhibitor and a potential mediator of extracellular antimitogenic signals. Cell 1994; 78: 59-66.

10. Besson A, Dowdy SF, Roberts JM. CDK inhibitors: cell cycle regulators and beyond. Dev Cell 2008; 14: 159-169.

11. Ladha MH, Lee KY, Upton TM, Reed MF, Ewen ME. Regulation of exit from quiescence by p27 and cyclin D1-CDK4. Mol Cell Biol 1998; 18: 6605-6615.

12. Ray A, James MK, Larochelle S, Fisher RP, Blain SW. p27Kip1 inhibits cyclin D-cyclindependent kinase 4 by two independent modes. Mol Cell Biol 2009; 29: 986-999.

13. Kwon TK, Nordin AA. Identification of cdk2 binding sites on the p27Kip1 cyclin-dependent kinase inhibitor. Oncogene 1998; 16: 755-762.

14. Teixeira LT, Kiyokawa H, Peng XD, Christov KT, Frohman LA, Kineman RD. p27Kip1deficient mice exhibit accelerated growth hormone-releasing hormone (GHRH)-induced somatotrope proliferation and adenoma formation. Oncogene 2000; 19: 1875-1884.

15. Fero ML, Randel E, Gurley KE, Roberts JM, Kemp CJ. The murine gene p27Kip1 is haploinsufficient for tumour suppression. Nature 1998; 396: 177-180.

16. Philipp-Staheli J, Payne SR, Kemp CJ. p27(Kip1): regulation and function of a haploinsufficient tumor suppressor and its misregulation in cancer. Exp Cell Res 2001; 264: 148-168.

17. Di Cristofano A, De Acetis M, Koff A, Cordon-Cardo C, Pandolfi PP. Pten and p27KIP1 cooperate in prostate cancer tumor suppression in the mouse. Nat Genet 2001; 27: 222-224.

18. Nohara T, Ryo T, Iwamoto S, Gon G, Tanigawa N. Expression of cell-cycle regulator p27 is correlated to the prognosis and ER expression in breast carcinoma patients. Oncology 2001; 60: 94-100.

19. Ogino S, Shima K, Nosho K, Irahara N, Baba Y, Wolpin BM et al. A cohort study of p27 localization in colon cancer, body mass index, and patient survival. Cancer Epidemiol Biomarkers Prev 2009; 18: 1849-1858.

20. Zhuang Y, Yin HT, Yin XL, Wang J, Zhang DP. High p27 expression is associated with a better prognosis in East Asian non-small cell lung cancer patients. Clin Chim Acta 2011; 412 : 2228-2231.

21. Chetty R. University Health Network PMHUAFFSTONMGMCrcuoc p27 Protein and cancers of the gastrointestinal tract and liver: an overview. J Clin Gastroenterol 2003; 37: 23-27.

22. Aoyagi K, Kouhuji K, Miyagi M, Imaizumi T, Kizaki J, Isobe T et al. Expression of p27Kip1 protein in gastric carcinoma. Hepato-gastroenterology 2013; 60: 390-394.

23. Wiksten JP, Lundin J, Nordling S, Kokkola A, von Boguslawski K, Haglund C. The prognostic value of p27 in gastric cancer. Oncology 2002; 63: 180-184.

24. So JB, Samarasinge K, Raju GC, Moochhala SM, Ti TK. Expression of cell-cycle regulators p27 and cyclin E correlates with survival in gastric carcinoma patients. J Surg Res 2000; 94: $56-60$.

25. Feakins RM, Mulcahy HE, Quaglia A, Jawhari A, Zhang Z, Patchett SE. p27(Kip1) loss does not predict survival in patients with advanced gastric carcinoma. Cancer 2000; 89: 1684-1691.

26. Philipp-Staheli J, Kim KH, Liggitt D, Gurley KE, Longton G, Kemp CJ. Distinct roles for p53, p27Kip1, and p21Cip1 during tumor development. Oncogene 2004; 23: 905-913.

27. Luo Z, Yu G, Lee HW, Li L, Wang L, Yang D et al. The Nedd8-activating enzyme inhibitor MLN4924 induces autophagy and apoptosis to suppress liver cancer cell growth. Cancer Res 2012; 72: 3360-3371.

28. Godbersen JC, Humphries LA, Danilova OV, Kebbekus PE, Brown JR, Eastman A et al. The Nedd8-activating enzyme inhibitor MLN4924 thwarts microenvironment-driven NF-kappaB 
activation and induces apoptosis in chronic lymphocytic leukemia B cells. Clin Cancer Res 2014; 20: 1576-1589.

29. Nicoli S, Presta M. The zebrafish/tumor xenograft angiogenesis assay. Nat Protoc 2007; 2: 2918-2923.

30. Tan DSW, Haaland B, Gan JM, Tham SC, Sinha I, Tan EH et al. Bosutinib inhibits migration and invasion via ack1 in kras mutant non-small cell lung cancer. Mol Cancer 2014; 13: 13.

31. White R, Rose K, Zon L. Zebrafish cancer: the state of the art and the path forward. Nat Rev Cancer 2013; 13: 624-636.

32. Tobia C, Gariano G, De Sena G, Presta M. Zebrafish embryo as a tool to study tumor/ endothelial cell cross-talk. Biochim Biophys Acta 2013; 1832: 1371-1377.

33. Liu S, Leach SD. Zebrafish models for cancer. Annu Rev Pathol 2011; 6: 71-93.

34. Yee $\mathrm{C}$, Yang $\mathrm{W}$, Hekimi $\mathrm{S}$. The intrinsic apoptosis pathway mediates the pro-longevity response to mitochondrial ROS in C. elegans. Cell 2014; 157: 897-909.

35. Du C, Fang M, Li Y, Li L, Wang X. Smac a mitochondrial protein that promotes cytochrome c-dependent caspase activation by eliminating IAP inhibition. Cell 2000; 102: 33-42.

36. Kim JY, Kim YJ, Seok KO, Lee S, Park JH. Caspase-9-dependent nuclear translocation of cytochrome $c$ in hypoxic injury. Pathobiology 2010; 77: 320-327.

37. Gao CF, Ren S, Zhang L, Nakajima T, Ichinose S, Hara T et al. Caspase-dependent cytosolic release of cytochrome $\mathrm{c}$ and membrane translocation of Bax in p53-induced apoptosis. Exp Cell Res 2001; 265: 145-151.

38. Dejean LM, Martinez-Caballero S, Kinnally KW. Is MAC the knife that cuts cytochrome c from mitochondria during apoptosis? Cell Death Differ 2006; 13: 1387-1395.

39. Deng X, Gao F, May Jr. WS Bcl2 retards G1/S cell cycle transition by regulating intracellular ROS. Blood 2003; 102: 3179-3185.

40. Cao X, Deng X, May WS. Cleavage of Bax to p18 Bax accelerates stress-induced apoptosis, and a cathepsin-like protease may rapidly degrade p18 Bax. Blood 2003; 102: 2605-2614.

41. Cao XH, Zhao SS, Liu DY, Wang Z, Niu LL, Hou LH et al. ROS-Ca(2+) is associated with mitochondria permeability transition pore involved in surfactin-induced MCF-7 cells apoptosis. Chem Biol Interact 2011; 190: 16-27.

42. Wood DE, Thomas A, Devi LA, Berman Y, Beavis RC, Reed JC et al. Bax cleavage is mediated by calpain during drug-induced apoptosis. Oncogene 1998; 17: 1069-1078.

43. Toyota H, Yanase N, Yoshimoto T, Moriyama M, Sudo T, Mizuguchi J. Calpain-induced Baxcleavage product is a more potent inducer of apoptotic cell death than wild-type Bax. Cancer Lett 2003; 189: 221-230.
44. Patel YM, Lane MD. Mitotic clonal expansion during preadipocyte differentiation: calpainmediated turnover of p27. J Biol Chem 2000; 275: 17653-17660.

45. Liang J, Zubovitz J, Petrocelli T, Kotchetkov R, Connor MK, Han K et al. PKB/Akt phosphorylates p27, impairs nuclear import of p27 and opposes p27-mediated G1 arrest. Nat Med 2002; 8: 1153-1160.

46. Shin I, Yakes FM, Rojo F, Shin NY, Bakin AV, Baselga J et al. PKB/Akt mediates cell-cycle progression by phosphorylation of p27(Kip1) at threonine 157 and modulation of its cellular localization. Nat Med 2002; 8: 1145-1152.

47. Sekimoto T, Fukumoto M, Yoneda Y. 14-3-3 suppresses the nuclear localization of threonine 157-phosphorylated p27(Kip1). EMBO J 2004; 23: 1934-1942.

48. Serres MP, Zlotek-Zlotkiewicz E, Concha C, Gurian-West M, Daburon V, Roberts JM et al. Cytoplasmic p27 is oncogenic and cooperates with Ras both in vivo and in vitro. Oncogene 2011; 30: 2846-2858.

49. Drexler HC, Pebler S. Inducible p27(Kip1) expression inhibits proliferation of K562 cells and protects against apoptosis induction by proteasome inhibitors. Cell Death Differ 2003; 10: 290-301.

50. Achenbach TV, Slater EP, Brummerhop H, Bach T, Muller R. Inhibition of cyclin-dependent kinase activity and induction of apoptosis by preussin in human tumor cells. Antimicrob Agents Chemother 2000; 44: 2794-2801.

51. Delmore JE, Issa GC, Lemieux ME, Rahl PB, Shi J, Jacobs HM et al. BET bromodomain inhibition as a therapeutic strategy to target c-Myc. Cell 2011; 146: 904-917.

(c) Cell Death and Disease is an open-access journal published by Nature Publishing Group. This work is licensed under a Creative Commons Attribution 4.0 International License. The images or other third party material in this article are included in the article's Creative Commons license, unless indicated otherwise in the credit line; if the material is not included under the Creative Commons license, users will need to obtain permission from the license holder to reproduce the material. To view a copy of this license, visit http://creativecommons.org/licenses/by/4.0/

Supplementary Information accompanies this paper on Cell Death and Disease website (http://www.nature.com/cddis) 